\title{
Strength Prediction of High-Strength Concrete by Fuzzy Logic and Artificial Neural Networks
}

\author{
Gökmen Tayfur ${ }^{1}$; Tahir Kemal Erdem²; and Önder Kırca, Ph.D. ${ }^{3}$
}

\begin{abstract}
High-strength concretes (HSC) were prepared with five different binder contents, each of which had several silica fume (SF) ratios $(0-15 \%)$. The compressive strength was determined at 3, 7, and 28 days, resulting in a total of 60 sets of data. In a fuzzy logic (FL) algorithm, three input variables (SF content, binder content, and age) and the output variable (compressive strength) were fuzzified using triangular membership functions. A total of 24 fuzzy rules were inferred from $60 \%$ of the data. Moreover, the FL model was tested against an artificial neural networks (ANNs) model. The results show that FL can successfully be applied to predict the compressive strength of HSC. Three input variables were sufficient to obtain accurate results. The operators used in constructing the FL model were found to be appropriate for compressive strength prediction. The performance of FL was comparable to that of ANN. The extrapolation capability of FL and ANNs were found to be satisfactory. DOI: 10.1061/(ASCE)MT.1943-5533.0000985. @ 2014 American Society of Civil Engineers.
\end{abstract}

Author keywords: Artificial intelligence; Cement; Concrete; Concrete admixtures; Compressive strength; High-strength concrete; Fuzzy sets.

\section{Introduction}

The design of high-strength concrete (HSC) requires more experience and knowledge of materials compared to normal-strength concretes. One has to consider both the chemical composition and physical properties of ingredients. Generally, HSCs are produced with a low water-to-binder ratio and high amounts of binder content. A greater complexity of design procedure may lead to more trial batches to check whether the required properties could be achieved or not (ACI 1993). However, this causes loss of time, manpower, and materials, resulting in a higher cost of the concrete. Therefore, some artificial intelligence methods such as artificial neural network (ANN) and fuzzy logic (FL) are very useful to predict the concrete strength, which helps to reduce the number of trial batches.

Recently, ANN has been employed for predicting concrete strength (Topçu and Sarıdemir 2008; Hong-Guang and Ji-Zong 2000; Öztaş et al. 2006; Yeh 1998; Dias and Pooliyadda 2001; Kasperkiewicz et al. 1995). For example, Öztaş et al. (2006) were able to predict the HSC strengths by ANN with a mean absolute percentage error of less than 2\%. Hong-Guang and JiZong (2000) stated that the results obtained by ANN modeling conform to some rules of concrete mix proportioning and are in good agreement with the experimental data. In another research paper, Yeh (1998) studied the modeling of strength of high-performance concrete and concluded that ANN models are more accurate than regression analyses where the ANN input parameters were cement, fly ash

\footnotetext{
${ }^{1}$ Professor, Civil Engineering Dept., Izmir Institute of Technology, Urla, 35430 Izmir, Turkey. E-mail: gokmentayfur@iyte.edu.tr

${ }^{2}$ Assistant Professor, Civil Engineering Dept., Izmir Institute of Technology, Urla, 35430 Izmir, Turkey (corresponding author). E-mail: tahirkemalerdem@iyte.edu.tr

${ }^{3}$ Director, CimSA Cement Production and Trading Co., Toroslar Mah. Yenitaskent, 33013 Mersin, Turkey. E-mail: o.kirca@cimsa.com.tr

Note. This manuscript was submitted on April 9, 2012; approved on November 15, 2013; published online on November 18, 2013. Discussion period open until November 2, 2014; separate discussions must be submitted for individual papers. This paper is part of the Journal of Materials in Civil Engineering, (C) ASCE, ISSN 0899-1561/04014079(7)/\$25.00.
}

(FA), ground granulated blast furnace slag, water, superplasticizer (SP), coarse aggregate, fine aggregate contents, and age, and the regression inputs were both test age and water-to-binder ratio. The better performance of ANN than regression models for concretes with admixtures was noted also by Dias and Pooliyadda (2001). Erdem et al. (2011) showed that ANN can successfully be used to predict the strengths of the binary and ternary binder systems. The binder types used in that study were portland cement, silica fume (SF), FA, slag, pumice powder, and metakaolin.

Although ANN has advantages, such as the ease of application and robustness, its main disadvantage is that it is a black-box model. No explicit relation between input and output variables can be obtained, which makes the results more difficult to interpret. However, in FL modeling, all the rules are written verbally, much like human thought. One can rapidly develop a set of rules based on knowledge and experience. This makes the fuzzy approach more user-friendly (Akkurt et al. 2004). Moreover, considering the type of data used in concrete strength modeling, FL may prove to be a better modeling tool. Such data are always associated with some error, which makes the fuzzy approach more suitable (Fa-Liang 1997).

Akkurt et al. (2004) predicted the 28-day cement strength by $\mathrm{ANN}$ and $\mathrm{FL}$ with input parameters $\mathrm{C}_{3} \mathrm{~S}, \mathrm{SO}_{3}$, total alkali contents, and Blaine surface area. It was concluded that successful predictions of the observed cement strength by the model indicate that fuzzy logic could be a useful modeling tool for engineers and research scientists in the area of cement and concrete.

It was shown in the literature that compressive strength values of mortars containing metakaolin (Sarıdemir 2009) and the strength of concretes containing low-lime and high-lime fly ash (Topçu and Sarıdemir 2008) can successfully be predicted by FL.

The prediction of strength of concretes with silica fume by FL was studied recently by Özcan et al (2009). The input parameters were selected as amount of cement, amount of silica fume replacement, water content, amount of aggregate, plasticizer content, and age of samples. Accurate results were obtained after constructing thousands of fuzzy rules $(7,200)$ on all of the data without performing calibration (training) and verification (testing) steps. Having rules in the order of hundreds or more is nothing more than a fitting 
process. This is because each data set has a fuzzy rule. Therefore, such a model would capture each data point without having a generalization capability. According to the common literature, including Şen (2004) and Tayfur (2012), a proper and efficient FL model shall have few variables and fuzzy rules. The model should also be calibrated and verified to prove its generalization.

In this study, HSC mixtures containing portland cement and silica fume (with several replacement ratios between 0 to $15 \%$ ) were produced in the laboratory. The total binder content varied between 500 and $700 \mathrm{~kg} / \mathrm{m}^{3}$. The compressive strengths were determined at 3, 7, and 28 days. After the determination of the strengths, the FL algorithm was used to predict the measured strengths. The input parameters used in the models were binder content, silica fume percentage and age, whereas the only output was the compressive strength. Just 24 fuzzy rules were established, using 36 out of 60 data sets (i.e., $60 \%$ of the data) in model calibration process. According to the literature, it is widely accepted that, at most, two-thirds of the data should be used for a proper training of the model (ASCE 2000; Şen 2004; Tayfur 2012). The remaining data sets were employed for verification. The performance of the prediction was evaluated by error analyses. Moreover, the extrapolation capability was also investigated. Finally, the FL model was tested against ANN for comparison purposes.

Fuzzy logic can be beneficial to describe real-world relationships that are inherently fuzzy. This is also true for the data used in this study: The relationship between the compressive strength and the studied variables (e.g., age, binder content, etc.) are not continuously increasing or decreasing. For example, silica fume content has an optimum value for a concrete mixture and this value depends on the binder content. For the values below and above the optimum value, strength at a certain age decreases. In such cases, the trend cannot be established easily.

Although there are several works regarding the artificial intelligence models for the estimation of compressive strengths of cements and blended concretes in the literature, this work focuses on HSC. Moreover, only a limited number of fuzzy rules (24) were established. Another difference of this work from the others is that extrapolation capability of the FL and ANN was studied for strength predictions of HSC.

\section{Experimental Program}

The cement used in this study was ordinary portland cement (PC), conforming to ASTM C150 Type I cement (ASTM 2002b), produced in the ÇimSa Cement Factory at Mersin, Turkey. Silica fume was from Antalya Ferrosilicon Plant. The properties of these binders are given in Table 1. A melamine-based, high-range, waterreducing admixture, classified as Type F according to ASTM C 494 (or superplasticizer) (ASTM 2002a), with 42\% solid particles was used.

Five different binder contents were employed: 500, 550, 600, 650 , and $700 \mathrm{~kg} / \mathrm{m}^{3}$. Four different aggregate groups (crushed limestone) were brought together to obtain a suitable grading according to the Turkish standards. Maximum aggregate size was $25 \mathrm{~mm}$. The grading of the aggregates was kept constant and the ratio of fine aggregates to coarse aggregates was 40/60 in all of the mixes. Water content was adjusted to secure a slump value of $6 \mathrm{~cm}$, and accordingly water/cementitious materials ratio was around 0.26 . The superplasticizer content was $3 \%$ of the total binder amount for all of the mixes.

A number of $15-\mathrm{cm}$ cube specimens were prepared and cured in water at $23^{\circ} \mathrm{C}$ until the testing ages. The compressive strengths of
Table 1. Properties of Binders

\begin{tabular}{lcc}
\hline Property & PC & SF \\
\hline $\mathrm{CaO}(\%)$ & 64.1 & 0.3 \\
$\mathrm{SiO}_{2}(\%)$ & 20.2 & 86.2 \\
$\mathrm{Al}_{2} \mathrm{O}_{3}(\%)$ & 5.2 & 0.0 \\
$\mathrm{Fe}_{2} \mathrm{O}_{3}(\%)$ & 2.6 & 0.4 \\
$\mathrm{Na}_{2} \mathrm{O}(\%)$ & 0.2 & 0.5 \\
$\mathrm{SO}_{3}(\%)$ & 3.2 & 0.4 \\
$\mathrm{LoI}(\%)$ & 1.4 & 1.5 \\
$\mathrm{Specific}$ gravity & 3.12 & 2.23 \\
Blaine fineness $\left(\mathrm{cm}^{2} / \mathrm{g}\right)$ & 3,350 & $\mathrm{ND}$ \\
Strength activity index at $7 \mathrm{~d}(\%)$ & - & 88 \\
Strength activity index at $28 \mathrm{~d} \mathrm{( \% )}$ & - & 98 \\
\hline
\end{tabular}

Note: ND = not determined.

Table 2. Compressive Strength Data of the HSC Mixtures

\begin{tabular}{lcccr}
\hline \multirow{2}{*}{$\begin{array}{l}\text { Binder content } \\
\left(\mathrm{kg} / \mathrm{m}^{3}\right)\end{array}$} & & \multicolumn{3}{c}{ Compressive strength $(\mathrm{MPa})$} \\
\cline { 3 - 5 } $500^{\mathrm{a}}$ & $\mathrm{SF}(\%)$ & $3-\mathrm{d}$ & $7-\mathrm{d}$ & $28-\mathrm{d}$ \\
& 0 & 40.4 & 50.0 & 55.1 \\
& 5 & 44.9 & 51.0 & 59.6 \\
$550^{\mathrm{b}}$ & 10 & 54.3 & 60.3 & 69.2 \\
& 15 & 51.5 & 62.4 & 72.0 \\
& 0 & 47.4 & 49.7 & 56.3 \\
$600^{\mathrm{a}}$ & 5 & 49.3 & 49.8 & 62.9 \\
& 10 & 51.5 & 55.1 & 62.5 \\
& 15 & 55.3 & 62.3 & 67.6 \\
$650^{\mathrm{b}}$ & 0 & 48.3 & 49.9 & 56.0 \\
& 5 & 52.2 & 56.1 & 60.1 \\
& 10 & 58.4 & 63.3 & 74.7 \\
$700^{\mathrm{a}}$ & 15 & 56.4 & 61.2 & 70.7 \\
& 0 & 56.1 & 58.0 & 65.1 \\
& 5 & 51.4 & 57.6 & 63.4 \\
& 10 & 59.5 & 63.5 & 65.9 \\
& 15 & 58.9 & 59.7 & 68.7 \\
& 0 & 51.9 & 50.3 & 54.2 \\
& 5 & 61.1 & 65.2 & 73.6 \\
& 10 & 58.0 & 62.4 & 72.6 \\
& 15 & 62.1 & 72.6 & 80.5 \\
\hline
\end{tabular}

${ }^{\mathrm{a}}$ Training data sets.

${ }^{\mathrm{b}}$ Testing data sets.

all mixtures were determined at 3,7 , or 28 days by determining the average of three specimens at each age. The strength results are given in Table 2. Because the main focus of this paper is on artificial intelligence methods, the details of the experimental work were left to the original study (Erdem and Kirca 2008).

The strength results were obtained by averaging the results of three specimens. The standard deviations of all of the mixtures were checked during the experimental stage and the mixtures were repeated again if their standard deviations were greater than $10 \%$. The standard deviations of the strength data in the paper are all less than $10 \%$.

\section{Overview of Fuzzy Logic Algorithm}

A general fuzzy system has four components-fuzzification, fuzzy rule base, fuzzy inference engine, and defuzzification (Fig. 1).

\section{Fuzzification}

The fuzzification component forms fuzzy sets for input-output variables using membership functions. Fuzzy membership functions 


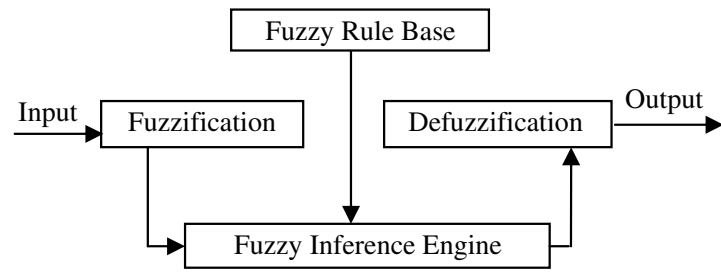

Fig. 1. Schematic representation of fuzzy system

may take many forms, but in practical applications there are two kinds of membership functions: (1) triangular and (2) bell-shaped (Gaussian). The literature has shown that although the triangular membership functions are commonly used and suggested, it does not really make a difference in using any of these functions (Şen 2004; Tayfur 2012). The advantage of using the triangular functions is that it is really easy to implement in the fuzzy toolbox of MATLAB.

Fig. 2, for example, presents triangular fuzzy membership functions for concrete strength. As displayed in Fig. 2, there are four fuzzy subsets-low, medium, high, and very high. The membership degree varies in between 0 and 1 (see the vertical axis where $m(S)$ stands for membership degree for strength). The key idea in fuzzy logic is that any object is allowed to partially belong to different subsets of universal set. For example, as seen in Fig. 2, there are four subsets in the strength universal set, and in this universal set $58 \mathrm{MPa}$ can be a member of both very high and high subsets with 0.2 and 0.8 membership degrees, respectively.

Intuition, rank ordering, and inductive reasoning can be among the many ways to assign membership functions to fuzzy variables. The intuitive approach is commonly used because it is simple and derived from the innate intelligence and understanding of human beings. Fuzzification presented in Fig. 2 is an example for the intuitive approach.

\section{Fuzzy Rule Base}

The fuzzy rule base contains rules that include all possible fuzzy relations between inputs and outputs. These rules are expressed in the IF-THEN format. There are basically two types of rule systems, Sugeno (1985) and Mamdani (1977). Depending upon the problem under consideration, a user can choose the appropriate rule system. The following rule is an example for Sugeno-type fuzzy rule:

IF binder content (B) is high, THEN strength (S) $S=a B^{b}$

The first part of a fuzzy rule (from IF to THEN part) is called as the antecedent part of the rule and the rest is called as the consequent part. In the Sugeno-type rule just described, the antecedent part of a rule contains a verbal statement but the consequent part involves a mathematical expression. In the Mamdani

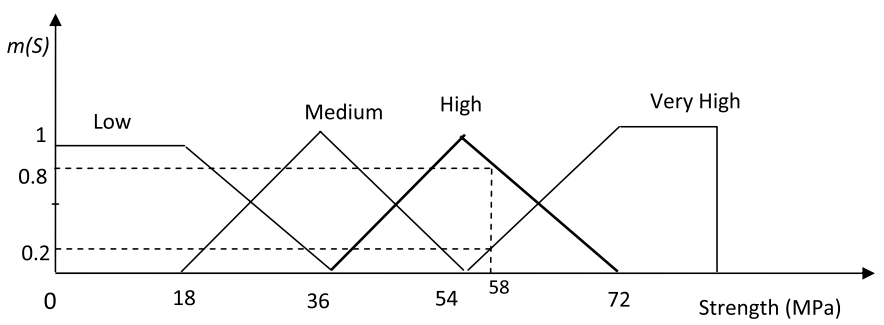

Fig. 2. Fuzzification of strength modeling

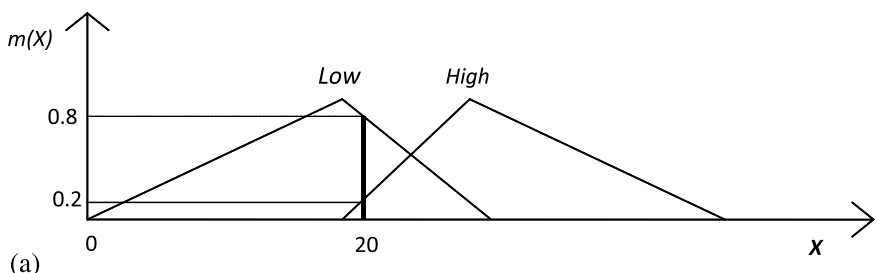

(a)

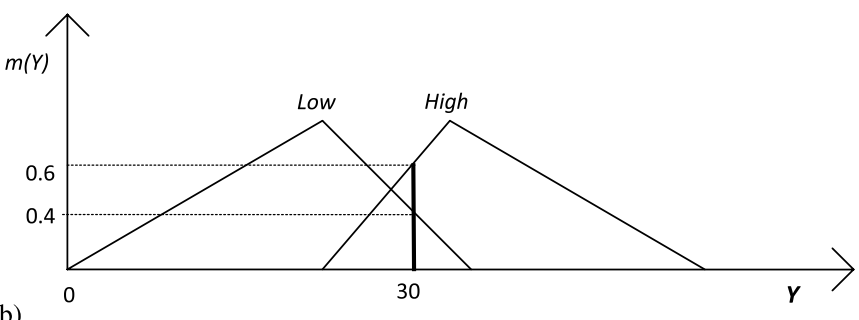

(b)

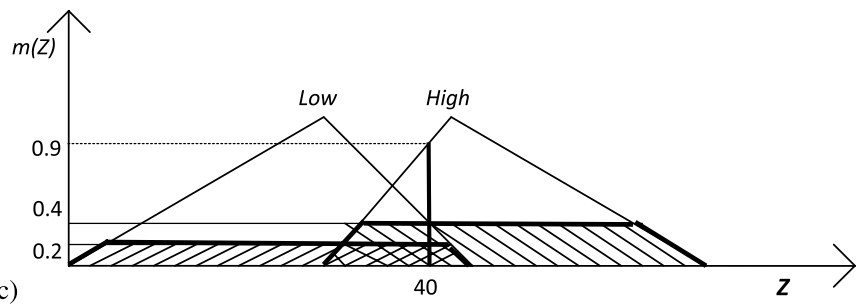

Fig. 3. Schematic representation of fuzzy inferencing: (a) $X=20$; (b) $Y=30$; (c) fuzzy output sets for $Z$

rule system, both antecedent and consequent parts of a rule contains verbal statements. The following is an example for a Mamdani rule:

IF binder content (B) is high THEN strength (S) is high

The Sugeno rule system is more appropriate for neuro-fuzzy systems (Şen 1998, unpublished notes, 1999; Jantzen 1999). Mamdani rules can be intuitively produced. They can also be constructed from available data. In order to illustrate the rule construction methodology, consider a simple case presented in Fig. 3, where there are two input variables of $X$ and $Y$ [Figs. 3(a and b)] and one output variable of $Z$ [Fig. 3(c)]. Assume that the measured (or observed) values of $X=20, Y=30$, and $Z=40$. According to Fig. 3(a), $X=20$ is part of high subset with 0.2 membership and low subset with 0.8 membership; $Y=30$ is part of low subset with 0.4 and high subset with 0.6 membership [Fig. 3(b)]; and $Z=40$ is part of low subset with 0.4 and high subset with 0.9 degree of membership [Fig. 3(c)]. According to rule derivation, as described in Tayfur (2012), one can have the following rule from this information:

IF $X$ is low AND $Y$ is high THEN $Z$ is high

As it can be understood from this constructed rule, the subsets corresponding to high-degree memberships as a result of $X, Y$, and $Z$ values are considered. The details of Mamdani rule construction methodology are given elsewhere (Tayfur 2012, 2006).

\section{Fuzzy Inference Engine}

The fuzzy inference engine takes into account all the fuzzy rules in the fuzzy rule base and learns how to transform a set of inputs to corresponding outputs. To do so, it uses either min or prod activation operators. The prod activation scales the membership curves, thus preserving the initial shape, rather than clipping them as the min activation does. Jantzen (1999) points out that both methods, 
in general, work well. In order to illustrate the inferencing methodology, the authors consider the case presented in Fig. 3. For this simple system, we also assume the following fuzzy rules:

IF $X$ is low and $Y$ is low THEN $Z$ is high

IF $X$ is high and $Y$ is high THEN $Z$ is low

Now, observe how the inference engine would produce fuzzy outputs for a given input vector of $X=20$ and $Y=30$. As seen in Fig. 3(a), $X=20$ is a part of low and high subsets with membership degrees of 0.8 and 0.2 , respectively. Similarly, $Y=30$ is part of low and high subsets with 0.4 and 0.6 degrees of membership, respectively [Fig. 3(b)]. When this input pair is fed into a fuzzy model, the inference engine would trigger the rules previously described. From the triggered first and second rules, the engine would find, by min operation, fuzzy output subsets of high and low, respectively, with different firing strengths.

The obtained subsets are schematically presented as shaded areas in Fig. 3(c), which shows that the triggered first rule results in high subset with 0.4 firing strength by min activation [i.e., min $(0.8,0.4)=0.4$; see Fig. 3(c), the shaded right trapezoid]. This value would be 0.32 by prod activation [i.e., prod $(0.8 \times 0.4=$ $0.32)]$. The triggered second rule would produce low subset with 0.2 firing strength [i.e., $\min (0.2,0.6)=0.2$; see Fig. 3 (c), the shaded left trapezoid]. This value would be 0.12 by prod activation [i.e., prod $(0.2 \times 0.6=0.12)$ ]. Note that inferencing does not produce a crisp output value but assigns whole fuzzy output subsets from each triggered rule to the output variable, like the two shaded areas in Fig. 3(c). The details of the inferencing subprocess can be found in Tayfur (2012).

The next subprocess in the inferencing engine is the composition where all of the fuzzy output subsets, obtained as a result of the activation operators from the triggered rules, are combined to form a single fuzzy subset for the output variable. For this purpose, there are basically two composition methods, maximization $(\max )$ and summation (sum). In max composition, the combined output fuzzy subset is constructed by taking the point-wise maximum over all of the fuzzy output subsets. As an example, the two shaded areas in Fig. 3(c) are combined, by taking the point-wise maximum over the two subsets, as presented in Fig. 4(a). In sum composition, the combined output fuzzy subset is constructed by taking the pointwise sum over all of the fuzzy output subsets. Consequently, in sum

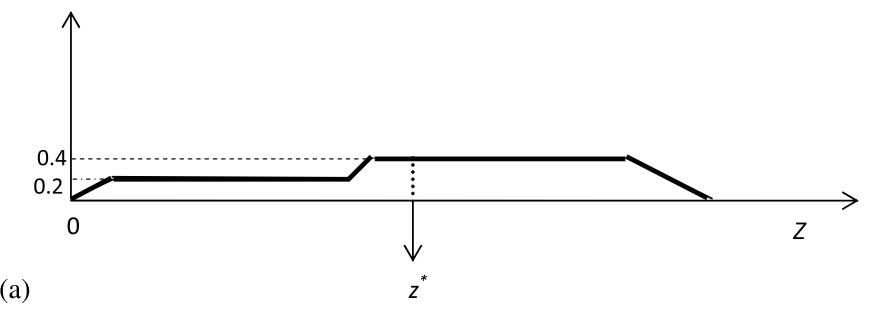

(b)

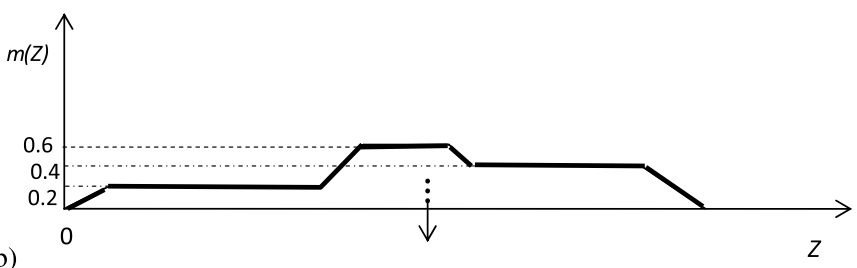

Fig. 4. Schematic representation of: (a) max composition and BOA defuzzification ( $z^{*}$ halves the whole set); (b) sum composition and COG defuzzification ( $z^{*}$ is the abscissa under the center of gravity of the whole set) composition it is sometimes possible to obtain truth values greater than one. Fig. 4(b) presents combined fuzzy output subset from the two shaded subsets in Fig. 3(c) by the sum composition. The details of the composition subprocess are given elsewhere (Tayfur 2012).

\section{Defuzzification}

Defuzzification converts the resulting fuzzy outputs from the fuzzy inference engine to a number. There are many defuzzification methods, such as center of gravity (COG), bisector of area (BOA), mean of maxima (MOM), leftmost maximum (LM), and rightmost maximum (RM). (Şen, unpublished notes, 1999; Jantzen 1999). The MOM, LM, and RM methods disregard the shape of the fuzzy set and as a result, they are employed in particular problems (Jantzen 1999). The BOA method picks the abscissa of the vertical line that divides the area of the combined fuzzy output subset in two equal halves. In Fig. 4(a), $z^{*}$ is assumed to halve the area and thus be the crisp value. In the centroid, or COG method, the crisp output value is the abscissa under the center of gravity of the combined fuzzy output subset. In Fig. 4(b), $z^{*}$ is assumed to be the centroid of the area and to be the crisp value. The centroid method is the most commonly used defuzzification method and for a discrete case it can be expressed as (Jantzen 1999)

$$
z^{*}=\frac{\sum_{i} \mu\left(z_{i}\right) z_{i}}{\sum_{i} \mu\left(z_{i}\right)}
$$

where $z^{*}$ is defuzzified output value; $z_{i}$ is output value in the $i$ th subset; and $\mu\left(z_{i}\right)$ is membership value of the output value in the $i$ th subset. For the continuous case, the summations in Eq. (1) are replaced by the integrals. The details of FL algorithm are available in the literature (Şen, unpublished notes, 1999; Tayfur 2012; Jantzen 1999).

\section{Artificial Neural Networks}

Artificial neural networks have an ability to identify patterns between input and output variables. In the commonly employed three-layer, feed-forward neural network (FFNN), the input quantities $\left(x_{i}\right)$ are fed into the input layer neurons which, in turn, pass them on to the hidden layer neurons $\left(z_{i}\right)$ after multiplying them by the connection weights $\left(v_{i j}\right)$. A hidden layer neuron adds up the weighted input received from each input neuron $\left(x_{i} v_{i j}\right)$, associates it with a bias $\left(b_{j}\right)$, and then passes the result $\left(\right.$ net $\left._{j}\right)$ on through the sigmoid transfer function, which can be sigmoid or tangent hyperbolic [tanh $(x)$ ] (Tayfur 2012).

Similarly, the outputs produced by the inner neurons are passed to the network output neuron. The net information received by the output neuron from the inner neurons is passed through the sigmoid function to produce the network output. The optimal weights are found by minimizing a predetermined error function $(E)$ of the following form (ASCE 2000):

$$
E=\sum_{P} \sum_{r}\left(y_{i}-t_{i}\right)^{2}
$$

where $y_{i}$ is the component of an ANN output vector $Y$; $t_{i}$ is the component of a target output vector $T ; r$ is the number of output neurons; and $P$ is the number of training patterns.

The gradient-descent method, along with the chain rule of differentiation, is generally employed to modify the network weights as (ASCE 2000)

$$
\Delta v_{i j}(n)=-\delta \frac{\partial E}{\partial v_{i j}}+\alpha \Delta v_{i j}(n-1)
$$




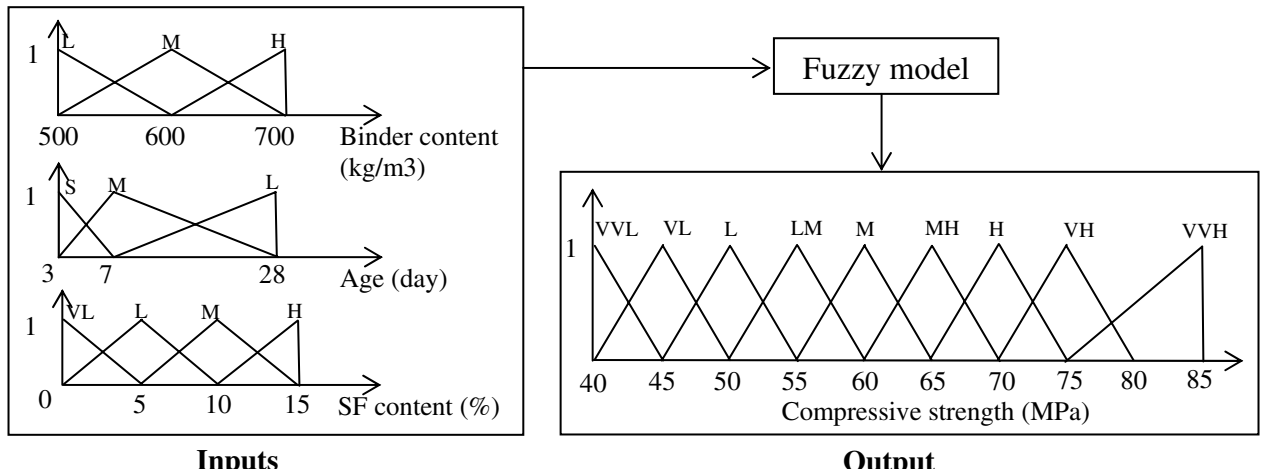

Fig. 5. Membership functions

where $\Delta v_{i j}(n)$ and $\Delta v_{i j}(n-1)$ are the weight increments between node $i$ and $j$ during the $n$th and $(n-1)$ th pass or epoch; $\delta$ is the learning rate; and $\alpha$ is the momentum factor. The details of ANNs can be obtained from Tayfur (2012).

\section{Data Sets and Model Construction}

\section{Fuzzy Logic}

In this study, binder content $\left(\mathrm{kg} / \mathrm{m}^{3}\right), \mathrm{SF}$ content (\%), and age (day) formed the input variables while strength $(\mathrm{MPa})$ was the output variable in the FL algorithm. Membership functions for input and output parameters used for fuzzy modeling are given in Fig. 5. The membership functions and the number of subsets were decided by considering the experimental data. The training and testing data tests are given in Table 2. The results for 500,600 , and $700 \mathrm{~kg} / \mathrm{m}^{3}$ binder contents were taken as training data sets while the other results were testing data. Therefore, there were 36 training data sets and 24 testing data sets.

The Mamdani-type fuzzy rules (Table 3) were developed using the procedure outlined previously. As described in Table 3, although there were 36 data sets used for the rule derivation, only 24 optimal rules were constructed. For Fig. 5, the binder content has 3 , the age has 3, the SF content has 4, and the strength variable has 9 fuzzy subsets. It is, in fact, theoretically possible to produce $3 \times 3 \times 4 \times 9=324$ fuzzy rules. However, such a fuzzy model would not have been proper, efficient, and user-friendly.

In inferencing, the min operator was used for finding the fuzzy output sets, resulting from corresponding triggered rules. The max composition operator was employed to combine these output sets into a single fuzzy output set. The centroid method was applied to find crisp output value from this output set during the defuzzification procedure. The fuzzy logic-based algorithm model was devised by using the fuzzy logic toolbox in MATLAB.

\section{Artificial Neural Network}

As was the case for FL, the input variables $\left(x_{i}\right)$ were binder content $\left(\mathrm{kg} / \mathrm{m}^{3}\right)$, SF content (\%), and age (day), while the output variable $\left(y_{i}\right)$ was the strength $(\mathrm{MPa})$ in the constructed three-layer FFNN. The training and testing data sets used for ANN were the same as those used for FL (Table 2). The results for 500, 600, and $700 \mathrm{~kg} / \mathrm{m}^{3}$ binder contents were taken as training data sets while the other results were testing data. Therefore, there were 36 training data sets and 24 testing data sets. The sigmoid function was employed as the activation function. Eqs. (2) and (3) are employed for computing global error and updating the network weights,
Table 3. The Fuzzy Rule Sets

\begin{tabular}{|c|c|c|c|c|}
\hline $\begin{array}{l}\text { Rule } \\
\text { number }\end{array}$ & $\begin{array}{l}\text { Binder } \\
\text { content }\end{array}$ & $\begin{array}{c}\text { SF } \\
\text { content }\end{array}$ & Age & $\begin{array}{c}\text { Compressive } \\
\text { strength }\end{array}$ \\
\hline 1 & $\mathrm{~L}$ & VL & S & VVL \\
\hline 2 & L & VL & M & $\mathrm{L}$ \\
\hline 3 & $\mathrm{~L}$ & VL & $\mathrm{L}$ & M \\
\hline 4 & $\mathrm{~L}$ & $\mathrm{~L}$ & S & VL \\
\hline 5 & $\mathrm{~L}$ & $\mathrm{~L}$ & M & $\mathrm{L}$ \\
\hline 6 & Not $\mathrm{H}$ & $\mathrm{L}$ & $\mathrm{L}$ & M \\
\hline 7 & Not $\mathrm{H}$ & M & $\mathrm{S}$ & LM \\
\hline 8 & Not $\mathrm{M}$ & M & M & M \\
\hline 9 & $\mathrm{~L}$ & M & $\mathrm{L}$ & $\mathrm{H}$ \\
\hline 10 & $\mathrm{~L}$ & $\mathrm{H}$ & S & $\mathrm{L}$ \\
\hline 11 & Not $\mathrm{H}$ & $\mathrm{H}$ & M & M \\
\hline 12 & Not $\mathrm{H}$ & $\mathrm{H}$ & $\mathrm{L}$ & $\mathrm{H}$ \\
\hline 13 & M & VL & Not L & $\mathrm{L}$ \\
\hline 14 & M & $\mathrm{L}$ & $\mathrm{S}$ & $\mathrm{L}$ \\
\hline 15 & M & $\mathrm{L}$ & M & LM \\
\hline 16 & M & M & $S$ & M \\
\hline 17 & M & M & M & MH \\
\hline 18 & Not L & M & $\mathrm{L}$ & MH \\
\hline 19 & $\mathrm{H}$ & $\mathrm{L}$ & $\mathrm{L}$ & VH \\
\hline 20 & $\mathrm{H}$ & $\mathrm{H}$ & M & $\mathrm{H}$ \\
\hline 21 & $\mathrm{H}$ & VL & Not L & $\mathrm{L}$ \\
\hline 22 & $\mathrm{H}$ & Not VL & $\mathrm{S}$ & M \\
\hline 23 & $\mathrm{H}$ & $\mathrm{L}$ & M & $\mathrm{MH}$ \\
\hline 24 & $\mathrm{H}$ & $\mathrm{H}$ & $\mathrm{L}$ & VVH \\
\hline
\end{tabular}

respectively. $\delta=0.01$ was the learning rate; and $\alpha=0.04$ was the momentum factor. The number of inner layer neurons was found by the trial and error procedure. Eq. (4) was employed for condensing the data into the range of 0.1 to 0.9

$$
x_{i}=0.1+\frac{0.8\left(x_{i}-x_{\min _{i}}\right)}{\left(x_{\max _{i}}-x_{\min _{i}}\right)}
$$

where $x_{\max }$ and $x_{\min }$ are the maximum and minimum values of the $i$ th neuron in the input layer for all the feed data vectors, respectively.

\section{Results and Discussions}

As seen in Table 2, the measured strengths of concretes containing $\mathrm{SF}$ (except the concretes with $5 \% \mathrm{SF}$ and $650 \mathrm{~kg} / \mathrm{m}^{3}$ binder content) are higher than those without SF for all ages. It was possible to obtain a compressive strength of as high as $62.1 \mathrm{MPa}$ at 3 days. In addition, strengths up to $80.5 \mathrm{MPa}$ could be obtained at 28 days. 
Note that higher binder content does not always result in higher compressive strength, as presented in State-of-the-Art Report on High-Strength Concrete (ACI 1997). The report states that there are several factors that may limit the maximum quantity of cement that may be desirable in a high-strength mixture. The strength of the concrete may decrease if cement is added above and beyond a given optimum content. For any given set of materials in a concrete mixture, there may be a cement content that produces maximum concrete strength. The maximum strength may not always be increased by the use of cement added to the mixture beyond this optimum cement content (ACI 1997). The inefficiency of increasing the binder content may be due to inherent inhomogeneity of the hydrated portland cement paste that contains randomly distributed areas of crystalline calcium hydroxide within the calcium-silicatehydrate gels. These areas present weak regions that are vulnerable to microcracking under tensile stress (Mehta and Monteiro 2006).

As stated earlier, prediction of the HSC mixtures containing SF was performed by FL which was also tested against ANN. The predicted versus measured strengths for both methods are given in Figs. 6-9, which indicate that both methods provide successful predictions. To have an objective comparison of the performance of the models, the mean relative error (MRE), the root-mean square

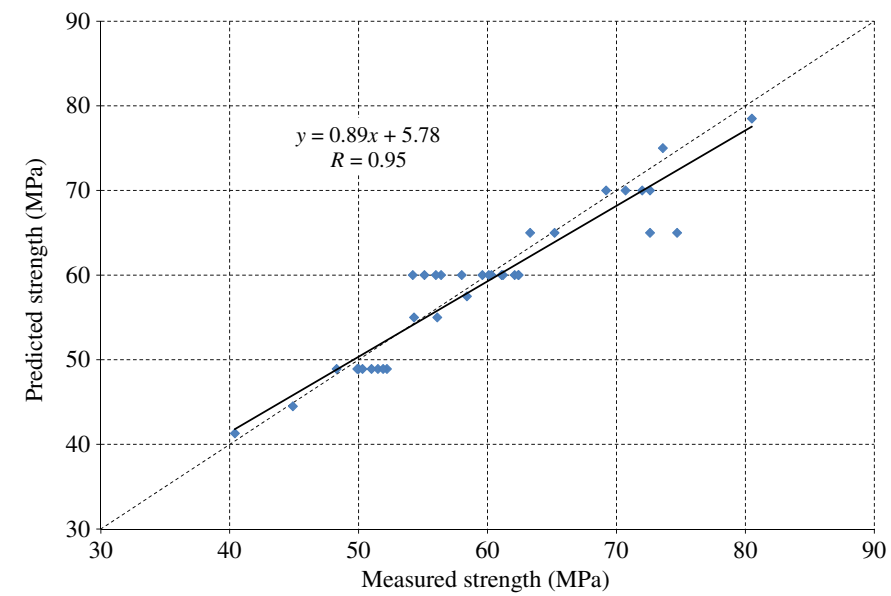

Fig. 6. Correlation of the measured and predicted strengths in training phase for FL modeling

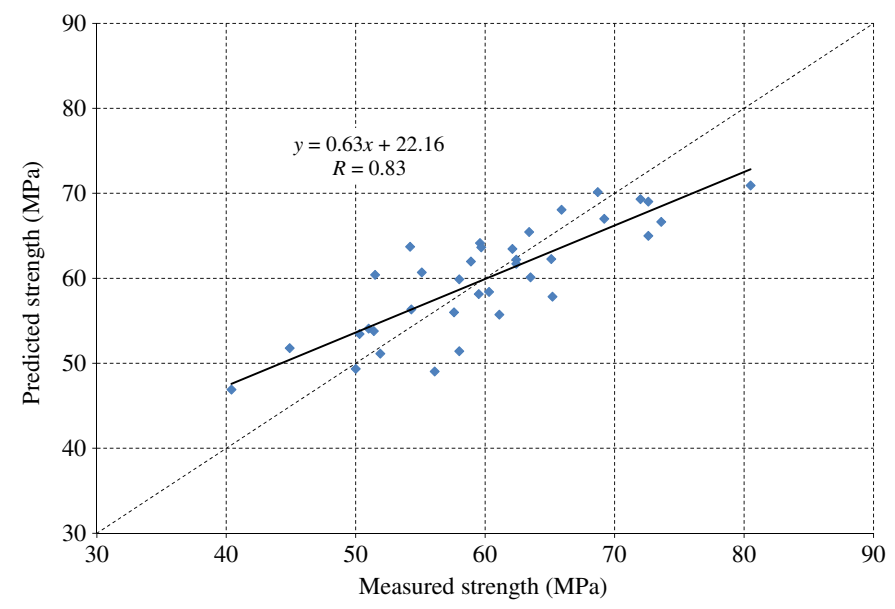

Fig. 7. Correlation of the measured and predicted strengths in training phase for ANN modeling

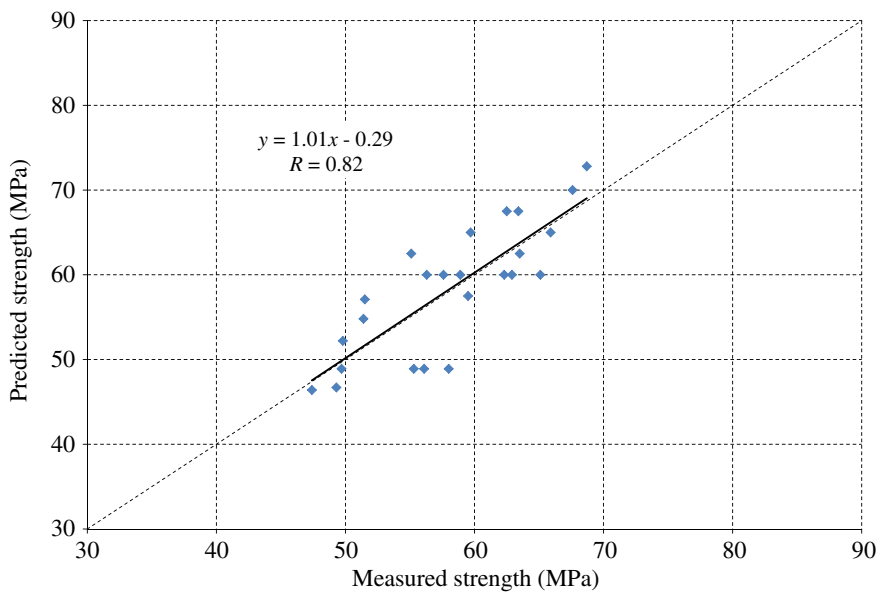

Fig. 8. Correlation of the measured and predicted strengths in testing phase for FL modeling

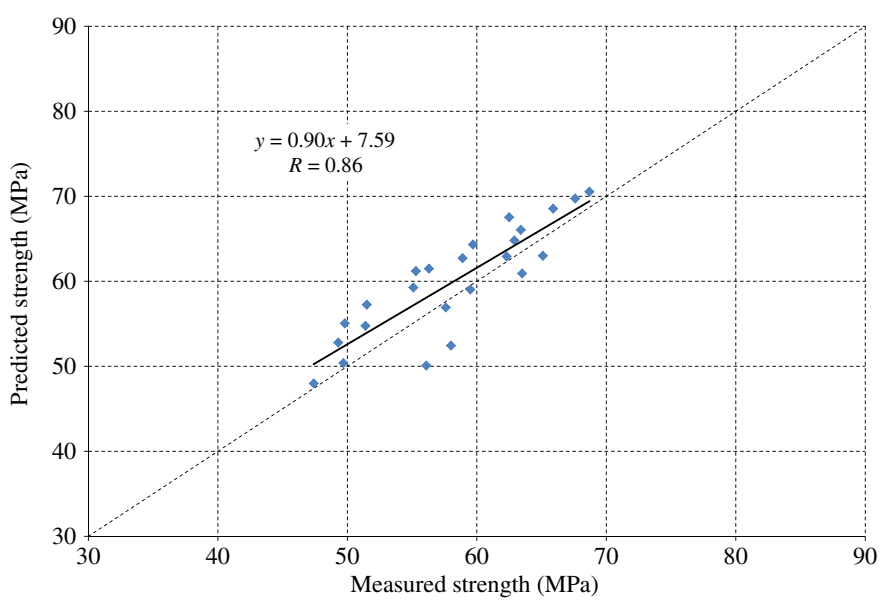

Fig. 9. Correlation of the measured and predicted strengths in testing phase for ANN modeling

Table 4. Error Analyses of the Prediction Methods

\begin{tabular}{lccccccc}
\hline & \multicolumn{3}{c}{ Training } & & \multicolumn{3}{c}{ Testing } \\
\cline { 2 - 4 } \cline { 8 - 9 } Method & $\begin{array}{c}\text { MRE } \\
(\%)\end{array}$ & MAE & RMSE & & MRE & MAE & RMSE \\
$(\mathrm{MPa})$ & $(\mathrm{MPa})$ & & $(\%)$ & $(\mathrm{MPa})$ & $(\mathrm{MPa})$ \\
\hline FL & 3.67 & 2.17 & 2.99 & & 6.44 & 3.68 & 4.31 \\
ANN & 6.68 & 3.91 & 4.74 & & 5.64 & 3.21 & 3.71 \\
\hline
\end{tabular}

error (RMSE) and the mean absolute error (MAE) for each prediction method are presented in Table 4.

For the training data sets, the coefficient of correlation $(R)$ was higher for FL compared to that of ANN (0.95 versus 0.83 , respectively), as can be seen in Figs. 6 and 7. The better performance of FL can also be observed in Table 4 since MRE, MAE, and RMSE values are lower for FL than those of ANN. It is worth to note that MRE, MAE, and RMSE values were as low as 3.7\%, 2.2 MPa, and 3.0 $\mathrm{MPa}$, respectively.

Comparison of Figs. 8 and 9 shows that $R$ is slightly higher for ANN than FL, indicating a better prediction by ANN than by FL. The errors shown in Table 4 are also slightly lower for ANN. On the other hand, the slope of the trend line fitted to the FL results shown 
in Fig. 8 is almost 1.0 and the intercept is close to zero. These indicate that desired results are produced not only by ANN but also by the FL model.

Also shown in Figs. 6-9 are the $45^{\circ}$ lines. The distribution of the data points in Figs. 6-9 is another indication of the success of both prediction methods. The number of the data points above and below the diagonal lines $\left(45^{\circ}\right.$ lines) is almost equal to each other for each figure. This indicates that models dominantly neither overestimates nor underestimates measured data.

Note that, as an extra test, the number of inputs was increased, and ANNs were applied once more by using the water amount and aggregate contents as inputs in the HSCs as well. However, including these inputs in the analyses did not improve the results significantly; i.e., the errors in Table 4 did not decay. This may be because the water/cementitious materials ratio range was narrow. Therefore, the binder content and the optimum amount of silica fume, which depends on the binder content, became more critical in the analyses. These inputs, together with the age, were sufficient to make the estimations. Since this analysis was already done by ANNs, the authors did not try the same thing for FL. Note that increasing number of parameters increases the number of rules that can make the FL model clumsy. As pointed out earlier, the desirable FL is the one with fewer variables and rules, which is exactly done in this paper.

The extrapolation capability of ANNs and FL was also investigated. For training both the models, the 500,550 , and $600 \mathrm{~kg} / \mathrm{m}^{3}$ binder content data sets were employed and the strength of concretes with 650 and $700 \mathrm{~kg} / \mathrm{m}^{3}$ binder content were predicted. The computed $R=0.81$, RMSE $=4.8 \mathrm{MPa}, \mathrm{MAE}=4.1$, and the means absolute relative error (MARE) $=6.5 \%$ for ANN and $R=0.80, \mathrm{RMSE}=4.67 \mathrm{MPa}, \mathrm{MAE}=3.8 \mathrm{MPa}$, and MARE $=$ $6.3 \%$ for FL. As one can compare these values to those of testing in Table 4, it is seen that the values are quite comparable. This proves the good extrapolation capability of the models. However, note that if the range for any of input and/or output variables in Fig. 5 is changed, then the model needs to be reconstructed, recalibrated, and revalidated.

\section{Conclusions}

The following conclusions can be drawn from this study:

- FL can accurately predict the compressive strengths of HSCs with silica fume. The performance of FL is comparable to that of ANN.

- Employing three input variables (binder content, age, and SF content) with 24 optimal fuzzy rules is sufficient for the FL model to make satisfactory compressive strength predictions. This has an important implication for practical applications.

- Satisfactory prediction of the compressive strength results may imply that min inferencing, max composition, and centroid operators in the FL model are appropriate for the data used in this study.

- ANNs and FL models have good extrapolation capabilities in predicting strength of high-strength concretes.

\section{References}

Akkurt, S., Tayfur, G., and Can, S. (2004). "Fuzzy logic model for the prediction of cement compressive strength." Cem. Concr. Res., 34(8), $1429-1433$.
American Concrete Institute (ACI) Committee 211. (1993). "Guide for selecting proportions for high strength concrete with portland cement and fly ash." ACI211.4R-93, Detroit, MI.

American Concrete Institute (ACI). (1997). State-of-the-art report on highstrength concrete, Committee 363, Detroit.

ASCE Task Committee on Application of Artificial Neural Networks in Hydrology. (2000). "Artificial neural networks in hydrology I: Preliminary concepts.” J. Hydrol. Eng., 10.1061/(ASCE)1084-0699 (2000)5:2(115), 115-123.

ASTM. (2002a). "ASTM C494/C494M-12 standard specification for chemical admixtures for concrete." Annual book of ASTM standards, West Conshohocken, PA.

ASTM. (2002b). "Standard specification for portland cement." Annual book of ASTM standards, West Conshohocken, PA.

Dias, W. P. S., and Pooliyadda, S. P. (2001). "Neural networks for predicting properties of concretes with admixtures." Constr. Build. Mater., 15(7), 371-379.

Erdem, T. K., and Kirca, Ö. (2008). "Use of binary and ternary blends in high strength concrete." Constr. Build. Mater, 22(7), 1477-1483.

Erdem, T. K., Tayfur, G., and Kirca, Ö (2011). "Experimental and modeling study of strength of high strength concrete containing binary and ternary binders." Cem. Wapno Beton, 16(4), 224-237.

Fa-Liang, G. (1997). "A new way of predicting cement strength-Fuzzy logic.” Cem. Concr. Res., 27(6), 883-888.

Hong-Guang, N., and Ji-Zong, W. (2000). "Prediction of compressive strength of concrete by neural networks." Cem. Concr. Res., 30(8), $1245-1250$

Jantzen, J. (1999). "Design of fuzzy controllers." Technical Rep., No:98-E864, Dept. of Automation, Technical Univ. of Denmark, Lyngby, Denmark.

Kasperkiewicz, J., Racz, J., and Dubrawski, A. (1995). "HPC strength prediction using artificial neural network." J. Comput. Civ. Eng., 10.1061/ (ASCE)0887-3801(1995)9:4(279), 279-284.

Mamdani, E. H. (1977). "Application of the fuzzy logic to approximate reasoning using linguistic synthesis." IEEE Trans. Comput., C-26(12), 1182-1191

MATLAB [Computer software]. Natick, MA, MathWorks.

Mehta, P. K., and Monteiro, P. J. M. (2006). Concrete microstructure, properties and materials, 3rd Ed., McGraw-Hill, New York.

Özcan, F., Atis, C. D., Karahan, O., Uncuoğlu, E., and Tanyıldızı, H. (2009). "Comparison of artificial neural network and fuzzy logic models for prediction of L-term compressive strength of silica fume concrete." Adv. Eng. Software, 40(9), 856-863.

Öztaş, A., Pala, M., Özbay, E., Kanca, E., Çağlar, N., and Bhatti, M. A. (2006). "Predicting the compressive strength and slump of high strength concrete using neural network." Constr. Build. Mater., 20(9), 769-775.

Sarıdemir, M. (2009). "Predicting the compressive strength of mortars containing metakaolin by artificial neural networks and fuzzy logic." Adv. Eng. Software, 40(9), 920-927.

Şen, Z. (1998). "Fuzzy algorithm for estimation of solar irradiation from sunshine duration." Sol. Energy, 63(1), 39-49.

Şen, Z. (2004). Fuzzy logic and system models in water sciences, Turkish Water Foundation, İstanbul, Turkey.

Sugeno, M. (1985). Industrial applications of fuzzy control, Elsevier Science, Amsterdam, The Netherlands.

Tayfur, G. (2006). "Fuzzy, ANN, and regression models to predict longitudinal dispersion coefficient in natural streams." Nordic Hydrology, $37(2), 143-164$.

Tayfur, G. (2012). Soft computing in water resources engineering, WIT, Southampton, England, U.K.

Topçu, İ. B., and Sarıdemir, M. (2008). "Prediction of compressive strength of concrete containing fly ash using artificial neural networks and fuzzy logic." Comput. Mater. Sci., 41(3), 305-311.

Yeh, I.-C. (1998). "Modeling of strength of high-performance concrete using artificial neural networks." Cem. Concr. Res., 28(12), 1797-1808. 